\title{
The role of the clinical pharmacist in the NICU: a cross-sectional survey of Australian and Polish pharmacy practice
}

\author{
Natalia Krzyżaniak, ${ }^{1}$ Iga Pawłowska, ${ }^{2}$ Beata Bajorek'
}

'Department of Pharmacy, University of Technology Sydney, Graduate School of Health (Pharmacy), Sydney, Australia

${ }^{2}$ Department of Pharmacology, Medical University of Gdańsk, Gdańsk, Poland

\section{Correspondence to}

Natalia Krzyżaniak, Department of Pharmacy, University of

Technology Sydney, Graduate School of Health (Pharmacy), Sydney, NSW 2007, Australia; Natalia.Krzyzaniak@student. uts.edu.au

Received 12 October 2017 Revised 1 December 2017 Accepted 12 December 2017 Published Online First 20 January 2018

\section{EAHP Statement 4: Clinical} Pharmacy Services. EAHP Statement 5: Patient Safety and Quality Assurance.

Check for updates

To cite: Krzyżaniak N, Pawłowska I, Bajorek B. Eur J Hosp Pharm 2018:25:e7-e16.

\begin{abstract}
Objectives To describe and compare the pharmaceutical services and clinical pharmacy roles performed in neonatal intensive care units (NICUs) in Australian versus Polish hospitals.
\end{abstract}

Methods A 26-item survey was distributed electronically to directors of pharmacy as well as neonatal pharmacists in hospitals in Poland and Australia. Most questions were fixed 'agree/disagree' answers, supplemented by open-ended questions. The survey was distributed between January and May 2017. Results Overall, 30 Australian pharmacists and 22 Polish pharmacists completed the survey. Significant differences were observed in the types of pharmaceutical care services provided to NICUs between Australia and Poland. A higher proportion of Australians than Poles performed clinical roles: for example, providing medication recommendations (Aus $=96.6 \%, \mathrm{Pol}=9.1 \%$, $\mathrm{P}<0.001)$; pharmaceutical interventions to resolve drug therapy problems (Aus=93.1\%, Pol=18.2\%, $\mathrm{P}<0.001)$; and general patient medication chart review (Aus $=96.6 \%$, Pol $=13.6 \%, \mathrm{P}<0.001)$. All (100\%) Polish pharmacists did not consider themselves members of the NICU team and the majority (59.1\%) felt that pharmaceutical care on the NICU was practically nonexistent.

Conclusion Future research should focus on bringing practice in countries such as Poland closer in line with practice in countries such as Australia.

\section{INTRODUCTION}

Approximately $16 \%$ of all live-born babies in Australia are admitted to special care nurseries (SCN) or neonatal intensive care units (NICUs). ${ }^{1}$ The majority of these newborns are pre-term with serious pathologies including infections, respiratory issues, jaundice and congenital malformations. ${ }^{12}$ To treat and manage these conditions, pharmacotherapy is widely used in conjunction with specialised medical interventions. It is reported that worldwide, NICU patients are prescribed a median range of three to 11 medications, with some babies requiring as many as $40 .{ }^{34}$ As such, the clinical pharmacist has an important role to play in the quality use of medicines in this patient group, potentially having a large impact on patient outcomes. ${ }^{5}$ The high incidence of off-label medicines use, polypharmacy and frailty in this patient group (characterised by young gestational ages, very small birthweights) increases the risk of medication errors and poses challenges to the safe and effective use of pharmacotherapy. ${ }^{6}$ Studies have shown that pharmacist-led interventions can improve medication management in the NICU: daily bedside reviews of medication orders, individualised total parenteral nutrition (TPN) regimens and education programmes, have been shown to reduce medication errors. ${ }^{78}$

Differences in healthcare systems, legislation, culture and tertiary education across countries may lead to the variable provision of pharmaceutical care services. The RIO Political Declaration for Health highlights that international healthcare systems should collaborate to develop coherent policies to promote consistent practice across settings within and between countries. ${ }^{9}$ Global collaboration is essential in identifying best practices for newborn patient care, however, little has been done to identify what roles are actually performed in NICUs worldwide, particularly between diverse countries such as Australia and eastern European countries, such as Poland. When considering the practice of hospital pharmacists in general in Australia and Poland, there are discernible differences. In Poland, general hospital pharmacists are restricted mainly to services in the dispensary, with limited clinical roles performed on wards. ${ }^{10} 11$ Pawłowska and Kocic $^{10}$ concluded that Polish hospital pharmacists were mainly involved in the distribution of medicines, such that patient-focused services were not common practice. In contrast, hospital pharmacist practice in Australia seems particularly clinically-focused. The Society of Hospital Pharmacists Australia (SHPA) advocates that pharmacists should have direct contact with patients, maintaining key roles in medication reconciliation, participating in ward rounds, providing medication information and monitoring drug therapy. ${ }^{12}$

Due to the lack of published literature in both countries it is unclear which pharmacy services are specifically performed in NICUs. Therefore, the purpose of this study was to compare the pharmaceutical services and clinical pharmacy roles performed in NICUs in Australian and Polish hospitals. The specific objectives included:

- identifying the roles currently performed by pharmacists in the NICU.

- describing the pharmacist's perceptions of their integration/role in the NICU team.

- identifying which roles are perceived by pharmacists as essential services to the NICU.

\section{METHODS}

A cross-sectional survey was electronically distributed to hospital pharmacists and directors of pharmacy departments employed in Australian and 
Polish hospitals with a NICU, between January and May 2017. Participants were assured of confidentiality and were informed that their responses would be de-identified.

\section{Participants}

This study involved the survey of NICU pharmacists as well as directors of pharmacy of hospitals that contained a NICU. Regardless of work status (ie, full-time/part-time), all Australian pharmacists that fulfilled these criteria were eligible to participate in the study. In Poland however, as clinical pharmacy practice is less developed, all hospital pharmacists and directors of pharmacy at hospitals containing a NICU were invited to complete the survey. Participants were identified through publicly available registers in Poland and Australia, that is, the Polish Register of Facilities delivering Medical Activities (Rejestr Podmiotów Wykonujących Działalność Leczniczą - RPWDL) and the Australian New Zealand Neonatal Network (ANZNN) that list hospitals with neonatal intensive care units. Furthermore, Australian participants were contacted via the Paedpharm online pharmacists group.

Using a significance level of $5 \%$ and a desired power of $80 \%$, a sample size calculation was performed for survey questions. The calculation was based on the precision around the point of estimate of effect, which is acknowledged as the estimated response to specific survey questions, based on the results of previous research. ${ }^{101113}$ A total of 64 participants was found to be the target sample size required.

\section{Survey}

The online survey (created in SurveyMonkey) was self-administered by participants. A total of 26 questions were developed following a comprehensive literature review. ${ }^{14}$ The majority of questions required fixed 'agree/disagree' answers, and were supplemented by open-ended questions. The questions canvassed the participant characteristics, which roles were performed by pharmacists specifically in, or for, NICUs (within four key categories: administrative, clinical, education, provision), identification of roles that were perceived as being essential to the NICU and an indication of the level of pharmacist integration in the multidisciplinary NICU team. All questions were pre-coded for data entry. The survey was pre-tested for content, design and readability in a small group of Australian pharmacists. The survey was administered in English and Polish for each respective country. For all surveys that were provided in Polish, the results were translated into English via a tiered process: survey results were translated from Polish to English by one researcher $(\mathrm{NK})$, then these translations were edited and verified by two co-researchers (IP, BB).

A unique survey link was emailed to each pharmacist. Respondents who requested a hard-copy version of the survey were sent one by post. Reminders were emailed to participants 1 month and 1 week before the end of the study period.

Surveys that were at least $50 \%$ completed by participants were included in the analysis. Incomplete responses were considered as missing values.

\section{Data analysis}

Descriptive statistics (percentages, frequencies) were used to analyse quantitative data via the Statistical Package for the Social Sciences (SPSS) Version 22. The Chi-square test was applied to test the association between independent categorical variables (eg, nationality - Australian and Polish) and dependent variables (eg, proportion of agree/disagree responses to questions relating to: roles that are performed by pharmacists specifically in or for NICUs and roles that are perceived as being essential to the NICU as well as pharmacist integration in the multidisciplinary NICU team). Statistical significance was accepted at a P value of $<0.05$.

Any qualitative data pertaining to pharmacist responses to open-answer questions were thematically analysed using manual inductive coding. Significant statements were identified from pharmacist responses and patterns were coded into non-overlapping themes and subthemes around the study objectives. ${ }^{15}$ Three researchers (NK, IP, BB) independently analysed the data before comparing the themes to attain consensus. The analysis was structured by an essentialist/realist theoretical framework which reflects on the experiences, meanings and the reality of participants. ${ }^{16}$ To ensure comprehension, the qualitative responses of participants are represented by the code 'AP' for Australian pharmacists and 'PP' for Polish pharmacists.

\section{RESULTS}

Due to the specialised nature of NICU pharmacy practice and the small number of NICUs in each country, the number of possible participants was limited. An accurate response rate is difficult to ascertain as it is unspecified how many Australian pharmacists have access to the Paedpharm online pharmacists group. Furthermore, it is also unknown how many surveys were distributed among colleagues within each hospital. As such, the response rate was calculated with the denominator being the number of surveys sent out electronically by researchers. A total of 55 surveys were sent out to Australian participants, with 30 responses received (response rate $=54.5 \%$ ), and 40 surveys were distributed to Polish participants, of which 22 returned a completed survey (response rate $=55 \%$ ) (table 1$)$.

Of the 30 participants from Australia and the 22 from Poland who completed the survey, $76.7 \%$ and $72.7 \%$ respectively were female (table 1). Most participants had between 1 to 5 years of practice experience (Aus $=43.3 \%, \mathrm{Pol}=54.5 \%$ ), and did not possess specialised qualifications related to neonatal or paediatric practice. More than half of the Polish participants (59.1\%) worked in the main hospital pharmacy (ie, dispensary). None of the pharmacists from Poland identified themselves as dedicated NICU pharmacists, in comparison to $44.8 \%$ of Australian pharmacists who did.

\section{Pharmacist interaction with the NICU}

While the majority of participants had contact with the NICU on a daily basis (Aus $=72.4 \%, \mathrm{Pol}=63.6 \%$ ), the nature of pharmacists' interaction with the ward differed between the two countries (table 2). A significantly higher proportion of Australian pharmacists $(93.3 \%)$ agreed that they provided pharmaceutical care services directly on the NICU, compared with Polish pharmacists $(4.5 \%, \mathrm{P}<0.001)$. Over a third of Australian pharmacists agreed that they spent an average of 1 - to 3 hours on the NICU ward per day, and $75 \%$ agreed that they covered all patient beds during this time.

All (100\%) Polish pharmacists reported that they worked in the main hospital pharmacy: half $(54.5 \%)$ stated that telephone contact was their only form of communication with the ward, as reinforced by their qualitative responses:

Co-operation is based on contact through the telephone between the ward and the compounding laboratory... Our collaboration is based on the completion of medication orders sent by the ward. PP6 
Table 1 Participant characteristics

\begin{tabular}{|c|c|c|}
\hline & Australia (\%) & Poland (\%) \\
\hline Number of respondents & 30 & 22 \\
\hline \multicolumn{3}{|l|}{ Gender of respondents } \\
\hline Female & $23(76.7)$ & $16(72.7)$ \\
\hline \multicolumn{3}{|l|}{ Qualifications } \\
\hline Bachelors Degree & $8(26.7)$ & 0 \\
\hline Masters Degree & $12(40)$ & $20(90.9)$ \\
\hline PhD Degree & $1(3.3)$ & 0 \\
\hline Qualifications held by participants other than those specified in the survey & $9(30)$ & $2(9.1)$ \\
\hline Post-graduate Certificate/Diploma & $9(30)$ & 0 \\
\hline Clinical pharmacy specialisation & 0 & $2(9.1)$ \\
\hline \multicolumn{3}{|l|}{ Specialised qualifications } \\
\hline Yes & $1(3.3)$ & 0 \\
\hline Postgraduate Certificate - (neonatal and paediatric-specific) & $1(3.3)$ & \\
\hline No & $29(96.7)$ & $22(100)$ \\
\hline Position in the hospital & $n=29$ & \\
\hline Neonatal pharmacist & $13(44.8)$ & 0 \\
\hline Director of pharmacy & $5(17.2)$ & $8(36.4)$ \\
\hline Pharmacist working in main hospital pharmacy & $3(10.3)$ & $13(59.1)$ \\
\hline Other & $8(27.6)$ & $1(4.5)$ \\
\hline Deputy Director & $1(3.4)$ & $1(4.5)$ \\
\hline Senior clinical pharmacist & $2(6.9)$ & \\
\hline Medicines information pharmacist & $2(6.9)$ & \\
\hline Specialist women, youth and children pharmacist & $2(6.9)$ & \\
\hline Aseptic CIVAS pharmacist & $1(3.4)$ & \\
\hline \multicolumn{3}{|l|}{ Experience } \\
\hline$<1$ year & $6(20)$ & $2(9.1)$ \\
\hline Between $1-5$ years & $13(43.3)$ & $12(54.5)$ \\
\hline Between 6-10years & $4(13.3)$ & $1(4.5)$ \\
\hline$>10$ years & $7(23.3)$ & $7(31.8)$ \\
\hline Number of beds in NICU (range) & $8-110$ & $4-28$ \\
\hline \multicolumn{3}{|c|}{$\begin{array}{l}\text { Definition of a Neonatal Intensive Care Unit } \\
\text { 'Neonatal unit that must be capable of assessing, diagnosing and managing all newborn infants requiring neonatal intensive care including infants: } \\
\text { requiring continuing assisted ventilation via an endotracheal tube, and for the } 24 \text { hours following endotracheal tube removal } \\
\text { requiring oxygen therapy (more than } 60 \% \text { ) for more than } 4 \text { hours } \\
\text { with tracheostomies requiring intermittent positive pressure ventilation (IPPV) or continuous positive airway pressure (CPAP) } \\
\text { requiring a nasopharyngeal tube (without CPAP) to maintain airway patency } \\
\text { requiring an arterial line for continuing blood gas and/or blood pressure monitoring } \\
\text { having frequent seizures - undergoing major surgery, on the day of the procedure and for } 48 \text { hours postoperatively, including: } \\
\text { - any procedure where a body cavity is opened } \\
\text { - repair of neural tube defect } \\
\text { - placement of a ventriculoperitoneal shunt or temporary ventricular drainage device } \\
\text { requiring } 1: 1 \text { nursing care }\end{array}$} \\
\hline
\end{tabular}

Collaboration is only associated with the preparation of drugs for the ward, formulations for individual patients such as powders, feeding bags or antibiotics... contact with doctors is very limited.

The most common contact is with the NUM. PP18

\section{Pharmacist roles currently performed in the NICU}

In Australia, pharmacists reported being frequently involved in direct-patient care and decision-making related to pharmacotherapy in the NICU (table 3). A significantly higher proportion of Australians than Poles agreed that they provided medication recommendations to medical staff (Aus $=96.6 \%$, Pol $=9.1 \%, \mathrm{P}<0.001$ ), intervened to resolve drug therapy problems (Aus $=93.1 \%, \mathrm{Pol}=18.2 \%$, $\mathrm{P}<0.001)$ and routinely reviewed patient medication charts (Aus $=96.6 \%$, Pol $=13.6 \%, \mathrm{P}<0.001)$. All $(100 \%)$ Australian participants reported that they were a source of medication information on the ward, and responded to queries raised by nursing and medical staff. Nine times as many Australians than Poles were involved in checking patient progress on prescribed pharmacotherapy (Aus $=96.6 \%$, Pol $=13.6 \%$, $\mathrm{P}<0.001$ ), along with therapeutic drug monitoring (TDM) (Aus=96.6\%, Pol $=13.6 \%, \mathrm{P}<0.001$ ) and recommending doses to medical and nursing staff (Aus $=96.6 \%$, Pol $=13.6 \%$, $\mathrm{P}<0.001$ ). Australian respondents often expressed that they focused on medication safety to reduce medication errors arising from prescribing (dosing, drug selection) or administration errors, in this high-risk patient population. Furthermore, Australian pharmacists emphasised their role in developing key medication guidelines and protocols for the NICU, which were heavily relied on by staff.

Prescribing and administration errors are unfortunately quite common in NICUs despite best practice drug guidelines available. Routine medication chart review and being present on ward rounds 


\begin{tabular}{|c|c|c|c|}
\hline & Australia (\%) & Poland (\%) & $\begin{array}{l}\text { P value } \\
\text { (Comparison of } \\
\text { proportions between } \\
\text { Australian and Polish } \\
\text { participants) }\end{array}$ \\
\hline Is there a pharmacist currently providing services directly on the NICU? & $\mathrm{n}=30$ & $\mathrm{n}=22$ & $<0.001$ \\
\hline Yes & $28(93.3)$ & $1(4.5)$ & \\
\hline No & $2(6.7)$ & $21(95.5)$ & \\
\hline Pharmacy administration/office & $2(100)$ & 0 & \\
\hline If not working directly in the NICU, does the pharmacist have any form of contact with the NICU? & $\mathrm{n}=2$ & $n=22$ & \\
\hline Yes - via phone & 0 & $12(54.5)$ & \\
\hline Yes - both phone and email & $1(50)$ & $9(40.9)$ & \\
\hline No & $1(50)$ & $1(4.5)$ & \\
\hline On request & 0 & $4(18.2)$ & \\
\hline How frequently does a pharmacist directly provide services in the NICU? & $n=29$ & $\mathrm{n}=1$ & \\
\hline Daily & $21(72.4)$ & $1(100)$ & \\
\hline 2-3 times per week & $3(10.3)$ & & \\
\hline Monthly & $1(3.4)$ & & \\
\hline On request & $1(3.4)$ & & \\
\hline Other & $3(10.3)$ & & \\
\hline Average duration of pharmacist visit on the NICU & $\mathrm{n}=29$ & $n=1$ & \\
\hline$<1$ hour & $2(6.9)$ & $1(100)$ & \\
\hline Between 1 and 3 hours & $12(41.4)$ & & \\
\hline Between 4 and 6 hours & $4(13.8)$ & & \\
\hline
\end{tabular}

where the majority of prescribing is done can minimise the risk of dose errors occurring... Regularly consulted for guideline development and drug selection. AP1

Medication safety focus, routine medication chart/pharmaceutical review, guideline review and development. AP16

Nursing staff have become reliant on medication guidelines and are hesitant to work outside of these guidelines without pharmacy involvement. AP17

Polish pharmacists reported being mostly involved in dispensary-based roles, including medication supply and administrative activities. Compared with the Australians, a higher proportion of Polish pharmacists identified that they were involved in dispensing ( $\mathrm{Pol}=100 \%$, Aus $=82.8 \%, \mathrm{P}=0.040)$, extemporaneous compounding ( $\mathrm{Pol}=95.5 \%$, Aus $=75.9 \%, \mathrm{P}=0.057$ ), house-keeping duties (ie, maintenance tasks e.g. stocking the ward with medicines, checking expiry dates; Pol $=100 \%$, Aus $=67.9 \%, \mathrm{P}=0.003)$ and purchasing pharmaceutical products for the NICU (Pol=95.5\%, Aus=72.4\%, P=0.033). None of the Polish pharmacists reported being involved in: training and education of medical staff; neonatal research; counselling parents/carers of patients; clinical meetings; evaluating patient laboratory tests; or ward rounds.

The pharmacist does not participate in ward rounds and has no knowledge of the patient's laboratory test results. They only become aware of problematic situations when the medical staff contact them. PP1

We do not participate in the processes of prescribing and monitoring pharmacotherapy. PP2

Role of a pharmacist is limited to the ordering of medicines - unused potential. PP7

Similar proportions of respondents from both countries reported monitoring of total parenteral nutrition (Aus $=86.2 \%$, Pol $=81.8 \%$ ), developing NICU drug formularies (Aus $=98.7 \%$, Pol=95.5\%), managing the NICU drug budget (Aus $=57.1 \%$, $\mathrm{Pol}=68.2 \%$ ) and attending non-clinical meetings (Aus $=72.4 \%$, Pol=77.3\%).

\section{Pharmacist expectations of roles that should be performed in the NICU}

Despite the differences in the types of pharmaceutical care services provided to NICUs between Australia and Poland, the majority of pharmacists in each country highlighted very similar expectations towards pharmacist practice. (table 4) The majority of respondents $(\geq 90 \%)$ from both countries agreed that pharmacists should undertake clinical roles, such as TDM (Aus $=100 \%$, Pol $=95 \%$ ), medication chart review (Aus=100\%, Pol=90\%) and checking patient response to prescribed pharmacotherapy 
Table 3 Roles that are performed by pharmacists in the NICU*

\section{Administrative roles}

\begin{tabular}{|c|c|c|c|}
\hline & Australia (\%) & Poland (\%) & $\begin{array}{l}\text { P value } \\
\text { (Comparison of proportions between } \\
\text { Australian and Polish participants) }\end{array}$ \\
\hline Development/implementation of a drug formulary service & $\begin{array}{l}26(89.7) \\
29\end{array}$ & $\begin{array}{l}21(95.5) \\
22\end{array}$ & 0.445 \\
\hline Attendance at non-clinical meetings that is, Drug and Therapeutics Committee & $\begin{array}{l}21(72.4) \\
29\end{array}$ & $\begin{array}{l}17(77.3) \\
22\end{array}$ & 0.693 \\
\hline $\begin{array}{l}\text { Conducting quality assurance measures that is, drug usage evaluations, workload } \\
\text { documentation, auditing }\end{array}$ & $\begin{array}{l}25(86.2) \\
29\end{array}$ & $\begin{array}{l}7(31.8) \\
22\end{array}$ & $<0.001$ \\
\hline Management of the drug budget & $\begin{array}{l}16(57.1) \\
28\end{array}$ & $\begin{array}{l}15(68.2) \\
22\end{array}$ & 0.425 \\
\hline Evaluation, selection and purchasing of pharmaceuticals for the unit & $\begin{array}{l}21(72.4) \\
29\end{array}$ & $\begin{array}{l}21(95.5) \\
22\end{array}$ & 0.033 \\
\hline Development of drug policies/protocols/guidelines for the NICU & $\begin{array}{l}28(96.6) \\
29\end{array}$ & $\begin{array}{l}5(22.7) \\
22\end{array}$ & $<0.001$ \\
\hline \multicolumn{4}{|c|}{ Clinical roles } \\
\hline & Australia (\%) & Poland (\%) & $\begin{array}{l}\text { P value } \\
\text { (Comparison of proportions between } \\
\text { Australian and Polish participants) }\end{array}$ \\
\hline Patient medication chart review & $\begin{array}{l}28(96.6) \\
29\end{array}$ & $\begin{array}{l}3(13.6) \\
22\end{array}$ & $<0.001$ \\
\hline Participation in medical ward rounds & $\begin{array}{l}25(86.2) \\
29\end{array}$ & $\begin{array}{l}0(0) \\
22\end{array}$ & $<0.001$ \\
\hline Monitoring the efficacy of pharmacotherapy in patients & $\begin{array}{l}28(96.6) \\
29\end{array}$ & $\begin{array}{l}3(13.6) \\
22\end{array}$ & $<0.001$ \\
\hline Documenting/monitoring adverse drug events/reactions & $\begin{array}{l}26(89.7) \\
29\end{array}$ & $\begin{array}{l}15(68.2) \\
22\end{array}$ & 0.056 \\
\hline Documenting medication errors & $\begin{array}{l}28(96.6) \\
29\end{array}$ & $\begin{array}{l}4(18.2) \\
22\end{array}$ & $<0.001$ \\
\hline Evaluating patients' clinical laboratory tests & $\begin{array}{l}28(96.6) \\
29\end{array}$ & $\begin{array}{l}0(0) \\
22\end{array}$ & $<0.001$ \\
\hline Therapeutic Drug Monitoring (TDM) & $\begin{array}{l}28(96.6) \\
29\end{array}$ & $\begin{array}{l}3(13.6) \\
22\end{array}$ & $<0.001$ \\
\hline Immunisations & $\begin{array}{l}19(67.9) \\
28\end{array}$ & $\begin{array}{l}1(4.5) \\
22\end{array}$ & $<0.001$ \\
\hline Monitoring Total Parenteral Nutrition (TPN) & $\begin{array}{l}25(86.2) \\
29\end{array}$ & $\begin{array}{l}18(81.8) \\
22\end{array}$ & 0.670 \\
\hline Participation in clinical meetings & $\begin{array}{l}23(79.3) \\
29\end{array}$ & $\begin{array}{l}0(0) \\
22\end{array}$ & $<0.001$ \\
\hline Calculating and recommending doses and dosing schedules for specific patients & $\begin{array}{l}28(96.6) \\
29\end{array}$ & $\begin{array}{l}3(13.6) \\
22\end{array}$ & $<0.001$ \\
\hline Assisting doctors in prescribing off-label/unlicensed medicines & $\begin{array}{l}28(96.6) \\
29\end{array}$ & $\begin{array}{l}6(27.3) \\
22\end{array}$ & $<0.001$ \\
\hline $\begin{array}{l}\text { Identifying and performing interventions for individual patients to prevent or resolve } \\
\text { drug therapy problems that is, interactions, incompatibilities, allergies etc. }\end{array}$ & $\begin{array}{l}27(93.1) \\
29\end{array}$ & $\begin{array}{l}4(18.2) \\
22\end{array}$ & $<0.001$ \\
\hline $\begin{array}{l}\text { Recommending drugs and contributing to the pharmacotherapy decision making process } \\
\text { for specific patients }\end{array}$ & $\begin{array}{l}28(96.6) \\
29\end{array}$ & $\begin{array}{l}2(9.1) \\
22\end{array}$ & $<0.001$ \\
\hline Collaborating and discussing specific patients with doctors and nurses & $\begin{array}{l}27(96.4) \\
28\end{array}$ & $\begin{array}{l}4(18.2) \\
22\end{array}$ & $<0.001$ \\
\hline \multicolumn{4}{|c|}{ Education/communication/research } \\
\hline & Australia (\%) & Poland (\%) & $\begin{array}{l}\text { P value } \\
\text { (Comparison of proportions between } \\
\text { Australian and Polish participants) }\end{array}$ \\
\hline $\begin{array}{l}\text { Providing training/in-services for other health professionals on NICU-related topics and } \\
\text { drug-related problems }\end{array}$ & $\begin{array}{l}27(93.1) \\
29\end{array}$ & $\begin{array}{l}0(0) \\
22\end{array}$ & $<0.001$ \\
\hline Contributing to and/or attending NICU-related conferences & $\begin{array}{l}22(75.9) \\
29\end{array}$ & $\begin{array}{l}7(31.8) \\
22\end{array}$ & 0.002 \\
\hline Involved in clinical trials & $\begin{array}{l}19(67.9) \\
28\end{array}$ & $\begin{array}{l}13(59.1) \\
22\end{array}$ & 0.522 \\
\hline
\end{tabular}




\begin{tabular}{|c|c|c|c|}
\hline & Australia (\%) & Poland (\%) & $\begin{array}{l}\text { (Comparison of proportions between } \\
\text { Australian and Polish participants) }\end{array}$ \\
\hline Involved in research related to neonatal pharmacotherapy & $\begin{array}{l}18(64.3) \\
28\end{array}$ & $\begin{array}{l}0(0) \\
22\end{array}$ & $<0.001$ \\
\hline Counselling parents/carers of neonatal patients & $\begin{array}{l}25(86.2) \\
29\end{array}$ & $\begin{array}{l}0(0) \\
22\end{array}$ & $<0.001$ \\
\hline & Australia (\%) & Poland (\%) & $\begin{array}{l}\text { P value } \\
\text { (Comparison of proportions between } \\
\text { Australian and Polish participants) }\end{array}$ \\
\hline Dispensing prescriptions & $\begin{array}{l}24(82.8) \\
29\end{array}$ & $\begin{array}{l}22(100) \\
22\end{array}$ & 0.040 \\
\hline Extemporaneous compounding of formulations for the NICU & $\begin{array}{l}22(75.9) \\
29\end{array}$ & $\begin{array}{l}21(95.5) \\
22\end{array}$ & 0.057 \\
\hline
\end{tabular}

*Proportions were calculated as the number of participants who responded to each question as the denominator.

(Aus $=100 \%$, Pol=90\%). All (100\%) Polish participants agreed that pharmacists should provide advice to medical staff when selecting medications and prescribing off-label products, as well as performing pharmaceutical interventions and collaborating with nursing and medical staff. Compared with Australian pharmacists, a significantly higher proportion of Polish participants expected that pharmacists should provide medication supply roles including dispensing $(\mathrm{Pol}=100 \%$, Aus $=73.9 \%, \mathrm{P}=0.014)$, extemporaneous compounding (Pol $=100 \%$, Aus $=60.9 \%$, $\mathrm{P}=0.002)$ and house-keeping activities ( $\mathrm{Pol}=100 \%$, Aus $=60.9 \%$, $\mathrm{P}=0.002)$. Furthermore, a significantly higher proportion of Poles than Australians agreed that administrative roles, such as management of the drug budget $(\mathrm{P}<0.001)$ and purchasing medications for the ward $(\mathrm{P}=0.027)$, should be performed by pharmacists.

Australian pharmacists, however, focused more on clinical roles, with $\geq 80 \%$ of respondents agreeing that 13 out of 15 roles listed in the 'clinical' category of the survey were expected to be performed. In their qualitative responses, overall, Australian participants felt there was a great need for pharmacist involvement in the care of this patient population. They described pharmacotherapy-related issues that were more prominent in neonatal patients, for example, interindividual variability in pharmacokinetics and dosing errors.

In Australia, NICUs are considered as areas that require essential clinical pharmacy services... Neonatal clinical pharmacist is essential for the medication/patient safety in this very high risk population to ensure the delivery of effective pharmacotherapy. AP6

Having a pharmacist permanently on NICU allows for consistency in patient care. I find on days that a pharmacist is unable to work in NICU that weaning of sedation/analgesia always gets missed, antibiotic doses aren't adjusted for age etc... AP24

\section{Pharmacist integration into the NICU environment}

All (100\%) Australians and $95.4 \%$ of Poles agreed that pharmacists should have visiting or permanent positions on the ward (table 5). However, differences were identified about the current level of pharmacist integration, with a significantly higher proportion of Polish pharmacists compared with Australian participants expressing that they were not considered to be members of the NICU team (Aus $=13.3 \%, \mathrm{Pol}=100 \%, \mathrm{P}<0.001$ ). In comparison, the majority of Australian pharmacists (86.7\%) reported being integral members of the NICU team. In their qualitative responses, they commonly described a respectful and collaborative relationship with the doctors and nurses, supported by effective communication. They stated that they were regularly approached on the ward to answer questions, being seen as a source of medication information.

Neonatal clinical pharmacist is a valuable NICU team member. AP6 Great multidisciplinary team-work. The NICU pharmacist is an integral part of the team. Effective rapport and communication between medical staff, nursing staff and pharmacist. Regular consultation for pharmacist input during medical rounds, and throughout the day. AP21

Stable member of the team. Well experienced NICU pharmacist plays a very important liaison role between rotating medical staff, nurses and patients and families. AP12

Polish participants noted that doctors would sometimes reach out to the pharmacy for assistance with pharmacotherapy-related problems encountered on the NICU, however, input into medication management was generally limited to the preparation and delivery of medications to the ward. Given the indirect nature of the contact, pharmacists emphasised they communicated more often with nurses, and that contact with doctors was 'rare'.

The level of contact is very formal, lack of awareness and confidence in pharmacists and their abilities. PP12

Doctors very rarely get in touch with the pharmacists, nurses do from time to time. PP16

A significantly higher proportion of Australian pharmacists (Aus $=70 \%$, Pol $=19 \%, \mathrm{P}<0.001$ ) identified that the current pharmacy services being delivered to NICUs in their local settings were meeting patient needs. In comparison, $81 \%$ of Polish pharmacists indicated that the pharmacotherapy requirements of neonatal patients were not being fulfilled by their pharmaceutical care system. Additionally, 59.1\% of Polish participants deemed that pharmaceutical care in the NICU was currently non-existent. 
Table 4 Pharmacist expectations towards roles that should be performed by pharmacists in NICU*

Administrative roles

\begin{tabular}{|c|c|c|c|}
\hline & Australia (\%) & Poland (\%) & $\begin{array}{l}\text { P value } \\
\text { (Comparison of proportions between } \\
\text { Australian and Polish participants) }\end{array}$ \\
\hline Development/implementation of a drug formulary service & $\begin{array}{l}19(86.4) \\
22\end{array}$ & $\begin{array}{l}21(100) \\
21\end{array}$ & 0.079 \\
\hline Attendance at non-clinical meetings, that is, Drug and Therapeutics Committee & $\begin{array}{l}13(59.1) \\
22\end{array}$ & $\begin{array}{l}21(100) \\
21\end{array}$ & 0.001 \\
\hline $\begin{array}{l}\text { Conducting quality assurance measures, that is, drug usage evaluations, workload } \\
\text { documentation, auditing }\end{array}$ & $\begin{array}{l}21(95.5) \\
22\end{array}$ & $\begin{array}{l}20(95.2) \\
21\end{array}$ & 0.973 \\
\hline Management of the drug budget & $\begin{array}{l}9(40.9) \\
22\end{array}$ & $\begin{array}{l}18(94.7) \\
19\end{array}$ & $<0.001$ \\
\hline Evaluation, selection and purchasing of pharmaceuticals for the unit & $\begin{array}{l}15(68.2) \\
22\end{array}$ & $\begin{array}{l}19(95) \\
20\end{array}$ & 0.027 \\
\hline Development of drug policies/protocols/guidelines for the NICU & $\begin{array}{l}22(100) \\
22\end{array}$ & $\begin{array}{l}17(81) \\
21\end{array}$ & 0.032 \\
\hline \multicolumn{4}{|c|}{ Clinical roles } \\
\hline & Australia (\%) & Poland (\%) & $\begin{array}{l}\text { P value } \\
\text { (Comparison of proportions between } \\
\text { Australian and Polish participants) }\end{array}$ \\
\hline Patient medication chart review & $\begin{array}{l}23(100) \\
23\end{array}$ & $\begin{array}{l}18(90) \\
20\end{array}$ & 0.120 \\
\hline Participation in medical ward rounds & $\begin{array}{l}20(83.3) \\
24\end{array}$ & $\begin{array}{l}15(75) \\
20\end{array}$ & 0.495 \\
\hline Monitoring the efficacy of pharmacotherapy in patients & $\begin{array}{l}24(100) \\
24\end{array}$ & $\begin{array}{l}18(90) \\
20\end{array}$ & 0.113 \\
\hline Documenting/monitoring adverse drug events/reactions & $\begin{array}{l}23(100) \\
23\end{array}$ & $\begin{array}{l}19(95) \\
20\end{array}$ & 0.278 \\
\hline Documenting medication errors & $\begin{array}{l}22(95.7) \\
23\end{array}$ & $\begin{array}{l}18(90) \\
20\end{array}$ & 0.468 \\
\hline Evaluating patient's clinical laboratory tests & $\begin{array}{l}20(87) \\
23\end{array}$ & $\begin{array}{l}8(40) \\
20\end{array}$ & 0.001 \\
\hline Therapeutic Drug Monitoring (TDM) & $\begin{array}{l}23(100) \\
23\end{array}$ & $\begin{array}{l}19(95) \\
20\end{array}$ & 0.278 \\
\hline Immunisations & $\begin{array}{l}13(54.2) \\
24\end{array}$ & $\begin{array}{l}5(25) \\
20\end{array}$ & 0.050 \\
\hline Monitoring Total Parenteral Nutrition (TPN) & $\begin{array}{l}18(78.3) \\
23\end{array}$ & $\begin{array}{l}19(95) \\
20\end{array}$ & 0.114 \\
\hline Participation in clinical meetings & $\begin{array}{l}19(82.6) \\
23\end{array}$ & $\begin{array}{l}17(85) \\
20\end{array}$ & 0.832 \\
\hline Calculating and recommending doses and dosing schedules for specific patients & $\begin{array}{l}21(95.5) \\
22\end{array}$ & $\begin{array}{l}17(85) \\
20\end{array}$ & 0.249 \\
\hline Assisting doctors in prescribing off-label/unlicensed medicines & $\begin{array}{l}23(95.8) \\
24\end{array}$ & $\begin{array}{l}20(100) \\
20\end{array}$ & 0.356 \\
\hline $\begin{array}{l}\text { Identifying and performing interventions for individual patients to prevent or resolve drug } \\
\text { therapy problems, that is, interactions, incompatibilities, allergies etc }\end{array}$ & $\begin{array}{l}23(100) \\
23\end{array}$ & $\begin{array}{l}20(100) \\
20\end{array}$ & Constant \\
\hline $\begin{array}{l}\text { Recommending drugs and contributing to the pharmacotherapy decision making process for } \\
\text { specific patients }\end{array}$ & $\begin{array}{l}21(91.3) \\
23\end{array}$ & $\begin{array}{l}20(100) \\
20\end{array}$ & 0.177 \\
\hline Collaborating and discussing specific patients with doctors and nurses & $\begin{array}{l}21(91.3) \\
23\end{array}$ & $\begin{array}{l}19(100) \\
19\end{array}$ & 0.188 \\
\hline \multicolumn{4}{|c|}{ Education/communication/research } \\
\hline & Australia (\%) & Poland (\%) & $\begin{array}{l}\text { P value } \\
\text { (Comparison of proportions between } \\
\text { Australian and Polish participants) }\end{array}$ \\
\hline $\begin{array}{l}\text { Providing training/in-services for other health professionals on NICU-related topics and } \\
\text { drug-related problems }\end{array}$ & $\begin{array}{l}20(87) \\
23\end{array}$ & $\begin{array}{l}19(95) \\
20\end{array}$ & 0.365 \\
\hline Contributing to and/or attending NICU-related conferences & $\begin{array}{l}16(66.7) \\
24\end{array}$ & $\begin{array}{l}17(89.5) \\
19\end{array}$ & 0.079 \\
\hline Involved in clinical trials & $\begin{array}{l}14(60.9) \\
23\end{array}$ & $\begin{array}{l}19(95) \\
20\end{array}$ & 0.008 \\
\hline
\end{tabular}




\section{Original article}

Table 4 Continued

Education/communication/research

\begin{tabular}{|c|c|c|c|}
\hline Involved in research related to neonatal pharmacotherapy & $16(64)$ & $17(85)$ & 0.113 \\
\hline & 25 & 20 & \\
\hline Source of drug information - responding to information requests from health professionals & $21(91.3)$ & $20(100)$ & 0.177 \\
\hline on the ward & 23 & 20 & \\
\hline Counselling parents/carers of neonatal patients & $23(95.8)$ & $16(84.2)$ & 0.193 \\
\hline & 24 & 19 & \\
\hline
\end{tabular}

Provision of medicines

$P$ value

(Comparison of proportions between

Australia (\%) Poland (\%) Australian and Polish participants)

Dispensing prescriptions

$17(73.9)$

$20(100)$

0.014

Extemporaneous compounding of formulations for the NICU

$14(60.9)$

20

23

Stocking the ward with essential medicines/house-keeping activities, that is, checking expiry

$14(60.9)$

$20(100)$

0.002

Stocking the ward with essential
dates, fridge temperatures etc

23

20

$20(100)$

0.002

*Proportions were calculated as the number of participants who responded to each question as the denominator.

\section{DISCUSSION}

The results from this study provide an insight into the types of clinical pharmacy services currently being delivered to NICUs in Australia and Poland. To date, there has been limited literature detailing pharmacist practice in the NICU in these countries. In order to promote the standardisation of practice, both nationally and worldwide, exploratory research needs to identify where gaps in practice lie.

According to the $\mathrm{WHO}$, pharmacists should incorporate seven roles into their practice regardless of the setting they

Table 5 Perceptions towards pharmacist integration into the NICU team*

\begin{tabular}{|c|c|c|c|}
\hline Should pharmacists be on the NICU? & $n=30$ & $n=22$ & \\
\hline Yes - routinely visiting & $15(50)$ & $18(81.8)$ & \\
\hline Yes - permanently stationed & $15(50)$ & $3(13.6)$ & \\
\hline No & 0 & $1(4.5)$ & \\
\hline Is the pharmacist currently considered part of multi-disciplinary NICU team? & $\mathrm{n}=30$ & $n=22$ & $<0.001$ \\
\hline Yes & $26(86.7)$ & $0(0)$ & \\
\hline No & $4(13.3)$ & $22(100)$ & \\
\hline $\begin{array}{l}\text { Should the pharmacist be consulted as part of the team when making pharmacotherapy- } \\
\text { related decisions? }\end{array}$ & $n=30$ & $n=22$ & 0.822 \\
\hline Yes & $29(96.7)$ & $21(95.5)$ & \\
\hline No & $1(3.3)$ & $1(4.5)$ & \\
\hline $\begin{array}{l}\text { Rate the current inter-professional relationship between pharmacists and the medical } \\
\text { and nursing staff }\end{array}$ & $\mathrm{n}=30$ & $\mathrm{n}=22$ & \\
\hline Good & $25(83.3)$ & $7(31.8)$ & \\
\hline Average & $3(10)$ & $7(31.8)$ & \\
\hline Poor & $1(3.3)$ & $7(31.8)$ & \\
\hline Non-existent & $1(3.3)$ & $1(4.5)$ & \\
\hline Rate current pharmaceutical care practice in the NICU & $\mathrm{n}=30$ & $\mathrm{n}=22$ & \\
\hline Good & $18(60)$ & $2(9.1)$ & \\
\hline Average & $10(33.3)$ & $3(13.6)$ & \\
\hline Poor & 0 & $4(18.2)$ & \\
\hline Non-existent & $2(6.7)$ & $13(59.1)$ & \\
\hline Are current pharmacy services meeting medication management needs in the NICU? & $\mathrm{n}=30$ & $n=21$ & $<0.001$ \\
\hline Yes & $21(70)$ & $4(19)$ & \\
\hline No & $9(30)$ & $17(81)$ & \\
\hline
\end{tabular}

*Proportions were calculated as the number of participants who responded to each question as the denominator. 
work in: care-giver, decision maker, communicator, manager, life-long learner, teacher and researcher. ${ }^{17}$ However, the roles that are actually implemented and provided to patients may vary. Our results highlight that pharmaceutical care delivered to NICUs in Australia and Poland does differ significantly. These variances mainly lie within the apparent value placed on pharmacist services in this unit, with the Polish system seemingly steered towards traditional roles, such as dispensing. In contrast, Australian pharmacists are seen to provide a progressive level of practice, comprising both clinical- and dispensary-based services. These findings are mirrored by those found in other limited studies based in Poland and Australia respectively. ${ }^{10} 111819$

While the contrasts seen in each country may be attributed to differences in pharmaceutical legislation, practice culture and pharmacist training, ultimately, each healthcare system should strive for consistency in the delivery of services to ensure equal healthcare opportunities for patients. The WHO identifies health equity as a priority for healthcare systems worldwide, in promoting uniform healthcare services between and within hospital settings. ${ }^{20}$ Standardised care is particularly important in critically ill patients, such as those in the NICU, whose outcomes depend on the provision of high-quality care that consistently meets their needs. However, the WHO recognises that one of the biggest challenges in improving patient safety, is the uniform implementation of best practices across hospital settings nationally or internationally. ${ }^{21}$ Leotsakos et.al. report that fluctuating patterns of healthcare services may result in varying patient outcomes and highlight that the standardisation of care practices can reduce costs, inefficiencies and risk. ${ }^{21}$ The WHO acknowledges that one of the most effective means of promoting practice uniformity is through the development of standardised practice tools that can be adapted and implemented in all hospital settings, both on a national and global scale, such as the WHO High 5's Project. ${ }^{21}$ A reported benefit to standardisation, is the ability to benchmark services between settings, which allows policy-makers as well as healthcare professionals to compare patient outcomes and to interpret the significance and value of an intervention. ${ }^{21}$ Ryan states that benchmarking of pharmacist services is best achieved using a three-tiered approach, comparing against best practice standards, against peers and against yourself, and over time. ${ }^{22}$ Given our findings that pharmacist practice varies significantly in Polish and Australian NICU settings, it is imperative that future research focuses on identifying how standards can be widely operationalised, to bring practice in countries such as Poland closer in line with practice in countries such as Australia.

\section{Limitations}

This survey was completed by only a proportion of hospital pharmacists in Australia and Poland, and may not be representative of all pharmacists in each country.

\section{CONCLUSION}

Pharmacist expectations of practice in the NICU were the same across both countries, however the actual pharmaceutical care services provided differed. Overall, the focus of pharmacy practice in NICUs in Australia and Poland is varied, ranging from clinically-centred services to traditional, dispensary-based medication supply duties respectively. However, the majority of participants from both countries highlighted that pharmacists should be involved in pharmacotherapy-related decision-making in the NICU. Disparities in practice may have varying influences on the health outcomes of a sensitive patient population. Future research should focus on promoting the standardisation of pharmaceutical care services to this ward through the development of practice guidelines and policies.

\section{What this paper adds}

\section{What is already known on this subject}

Differences in healthcare systems, legislation, culture and tertiary education across countries may lead to the variable provision of pharmaceutical care services. Global collaboration is essential in identifying best practices for newborn patient care. However, little has been done to identify which pharmacist roles are actually performed in NICUs worldwide.

\section{What this study adds}

The results from this study provide an insight into the types of clinical pharmacy services currently being delivered to NICUs in Australia and Poland. Pharmacist expectations of practice in the NICU were the same across both countries, however the actual pharmaceutical care services provided differed. Overall, the focus of pharmacy practice in NICUs in Australia and Poland is varied, ranging from clinically-centred services to traditional, dispensarybased medication supply duties respectively.

Acknowledgements The authors would like to thank all of the pharmacists and directors of pharmacy in hospitals in Australia and Poland for their invaluable assistance and co-operation.

Contributors NK, IP and BB contributed to the design and implementation of the research, to the analysis of the results and to the writing of the manuscript.

Competing interests None declared.

Ethics approval Ethics approval was obtained from the respective human research ethics committees at the University of Technology Sydney, Australia (REF NO. ETH161033) and the Medical University of Gdansk, Poland (REF NO. NKBBN/424/2016).

Provenance and peer review Not commissioned; externally peer reviewed.

(C) European Association of Hospital Pharmacists (unless otherwise stated in the text of the article) 2018. All rights reserved. No commercial use is permitted unless otherwise expressly granted.

\section{REFERENCES}

1 Australian Institute of Health and Welfare. Australia's Mothers and Babies 2013 - In Brief. Perinatal statistics. Canberra: Australian Institute of Health and Welfare, 2015.

2 Newborn conditions Australia: Department of Health \& Human Services, State Government of Victoria, 2015. https://www2.health.vic.gov.au/hospitals-and-healthservices/patient-care/perinatal-reproductive/neonatal-ehandbook/conditions (accessed 23 Jul 2016)

3 Neubert A, Lukas K, Leis T, et al. Drug utilisation on a preterm and neonatal intensive care unit in Germany: a prospective, cohort-based analysis. Eur J Clin Pharmacol 2010;66:87-95.

4 Krzyżaniak N, Pawłowska I, Bajorek B. Review of drug utilization patterns in NICUs worldwide. J Clin Pharm Ther 2016;41:612-20.

5 Erickson AK. Neonatal pharmacist to the rescue: caring for the hospital's most vulnerable patients: American Pharmacists Association. 2015 http://www.pharmacist. com/neonatal-pharmacist-rescue-caring-hospital-s-most-vulnerable-patients (accessed $21 \mathrm{Jul} 2016)$

6 Krzyzaniak N, Bajorek B. Medication safety in neonatal care: a review of medication errors among neonates. Ther Adv Drug Saf 2016;7:102-19.

7 Simpson JH, Lynch R, Grant J, et al. Reducing medication errors in the neonatal intensive care unit. Arch Dis Child Fetal Neonatal Ed 2004;89:F480-F482.

8 Dice JE, Burckart GJ, Woo JT, et al. Standardized versus pharmacist-monitored individualized parenteral nutrition in low-birth-weight infants. Am J Hosp Pharm 1981;38:1487-9

9 Rio Political Declaration on Social Determinants of Health Rio de Janeiro: World Health Organisation. 2011. http://www.who.int/sdhconference/declaration/Rio_ political_declaration.pdf?ua=1 (accessed 23 Jul 2016).

10 Pawłowska I, Kocić I. Rational use of medicines in the hospitals of Poland: role of the pharmacists. Eur J Hosp Pharm 2014;21:372-7.

11 Pawłowska I, Pawłowski L, Kocić I, et al. Clinical and conventional pharmacy services in Polish hospitals: a national survey. Int J Clin Pharm 2016;38:271-9. 
12 Taylor G, Leversha A, Archer C, et al. Standards of practice for clinical pharmacy services. J Pharm Pract Res 2013;43:2-5.

13 O'Leary KM, Allinson YM. Pharmacy clinical and distribution service delivery models in Australian public hospitals. J Pharm Pract Res 2004;34:114-21.

14 Krzyzaniak N, Bajorek B. A global perspective of the roles of the pharmacist in the NICU. Int J Pharm Pract 2017;25:107-20.

15 Thomas DR. A general inductive approach for qualitative data analysis. Am J Eval 2006;27:237-46.

16 Braun V, Clarke V. Using thematic analysis in psychology. Qual Res Psychol 2006:3:77-101.

17 Wiedenmayer K, Summers SR, Mackie CA, et al. Developing pharmacy practice - $A$ focus on patient care. The Netherlands: World Health Organisation, International Pharmaceutical Federation, 2006:14-16.
18 Swieczkowski D, Merks P, Gruchala M, et al. The role of the pharmacist in the care of patients with cardiovascular diseases. Kardiol Pol 2016;74:1319-26.

19 Gilbar P, Stefaniuk K. The role of the pharmacist in palliative care: results of a survey conducted in Australia and Canada. J Palliat Care 2002;18:287-92.

20 World Health Organisation. Health systems - equity. 2017. http://www.who.int/ healthsystems/topics/equity/en/ (accessed 14 Aug 2017).

21 Leotsakos A, Zheng H, Croteau R, et al. Standardization in patient safety: the WHO High 5s project. Int I Qual Health Care 2014;26:109-16.

22 Ryan M. Benchmarking and Hospital Pharmacy: Pharmacy Focus, 2014. http://www. apha.org.au/wp-content/uploads/2014/11/Pharmacy-Focus.pdf (accessed 14 Aug 2017).

23 Neonatal Service Guidelines. In: H S, ed. Defining levels of care in Victorian Hospitals. Melbourne: Victorian Government, 2005. 